\title{
Prosthetic rehabilitation of maxillary anterior region using implant supported restoration - A case report
}

\author{
Gita Rani ${ }^{1}$ and Amarjeet Gambhir ${ }^{2 *}$ \\ ${ }^{1}$ Department of Prosthodontics, Christian Dental College, Ludhiana, Punjab, India \\ ${ }^{2}$ Department of Dental \& Oral Surgery, Lady Hardinge Medical College \& Hospital, New Delhi, India
}

\begin{abstract}
Achieving an aesthetic implant-supported restoration in the anterior region can be a challenging task. The treatment planning for an implant restoration is unique regarding the number of variables that may influence the therapy. Collection of patient's information, appropriate abutment selection, soft tissue contour, implant axis, and occlusion need to be collectively emphasized for aesthetic clinical outcome. This case report describes the successful prosthetic rehabilitation of maxillary anterior region in a patient using implant supported restoration.
\end{abstract}

\section{Introduction}

The use of dental implants to replace missing teeth in the esthetic zone is a preferred treatment option. However, achieving functional and aesthetic implant-supported restorations in maxillary anterior region in a partially edentulous patient can be particularly challenging. The current definition of success in addition to long-term predictability, function and integration of the implant focuses on esthetic considerations [1,2]. In the anterior maxilla this is more critical due to the visibility of the region. If a high lip line is present, the smile line is more revealing thus increasing the need for an esthetic result, with some authors ranking function and aesthetics in the anterior maxillary region to be of equal importance [3-6].

This case report describes a step-by-step approach to prosthetic rehabilitation of maxillary anterior region in a patient using implantsupported restoration that resulted in an esthetically pleasing smile.

\section{Case report}

A 24-year-old male reported to the Department of Prosthodontics with the chief complaint of missing front teeth due to road traffic accident. On intraoral examination, it was revealed that there were missing teeth with respect to $11,12,21,22,31,32,41,42 \& 43$. Implant supported prosthesis was planned for the patient.

\section{Clinical procedure}

The patient reported after the surgical placement of implants in $11,12,21,22,32,42,43$ regions (Figure 1). Radiographic assessment after 6 months showed satisfactorily integrated implants (Figure 2). The healing abutments were removed, and impression copings placed (Figure 3) followed by Poly Vinyl Siloxane impression to capture implant positions (Figure 4). The impression copings were removed, and healing abutments replaced; shade selection was then done. Abutments were placed (Figure 5) and radiographs were taken to confirm the seating of the abutments (Figure 6). The abutments were then torqued to $35 \mathrm{~N}$ with the help of a torque wrench. The final crowns were then tried in. The occlusion was checked to ensure light contact in maximum intercuspation with no contact in protrusive and lateral excursions. The crowns were then cemented using a resin-modified glass ionomer cement. Excess cement was removed, and the occlusion verified (Figure 7). Patient was recalled after 3 months, 6 months and subsequently after a year with satisfactory results (Figure 8).

\section{Discussion}

Alternate treatment modalities to our treatment plan included a removable partial denture, fixed partial dentures and resin bonded bridges (Maryland bridges). Removable partial dentures though an option can contribute to the loss of alveolar bone on both abutment and non-abutment teeth and have a generally high dissatisfaction rate ranging from 9-26\% [7]. On the other hand, the use of fixed partial dentures would have required the unnecessary destruction of adjacent teeth to prepare them as abutments and loss of pristine tooth structure. Another option would have been a resin bonded bridge which would reduce the amount of destruction of adjacent teeth but with a high incidence of pontic failure and debonding [8]. Therefore, implants were considered to be the best option. Proper prosthetic concepts must be followed to maximize aesthetics and function of implant supported restoration. The clinician must consider the time needed for implant integration and soft-tissue healing, creation of emergence profiles, and occlusal forces on the final restoration. For an aesthetic restorative treatment, a precise examination and an accurate surgical stent should be made. Certain factors which need to be considered before placement of implant restorations include:

*Correspondence to: Amarjeet Gambhir, Lady Hardinge Medical College \& Hospital, New Delhi, India, Tel: +917982172082, +918427543060; E-mail: amarjeetgambhir@gmail.com

Key words: implant supported restoration, abutment, occlusion, prosthetic rehabilitation

Received: December 27, 2019; Accepted: January 08, 2020; Published: January 13,2020 


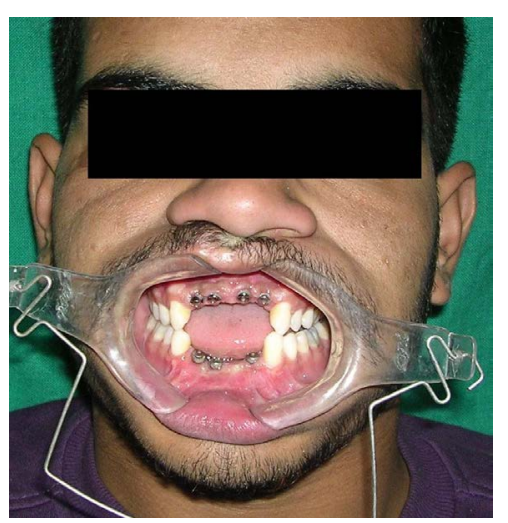

Figure 1. Clinical photograph after surgical placement of implants

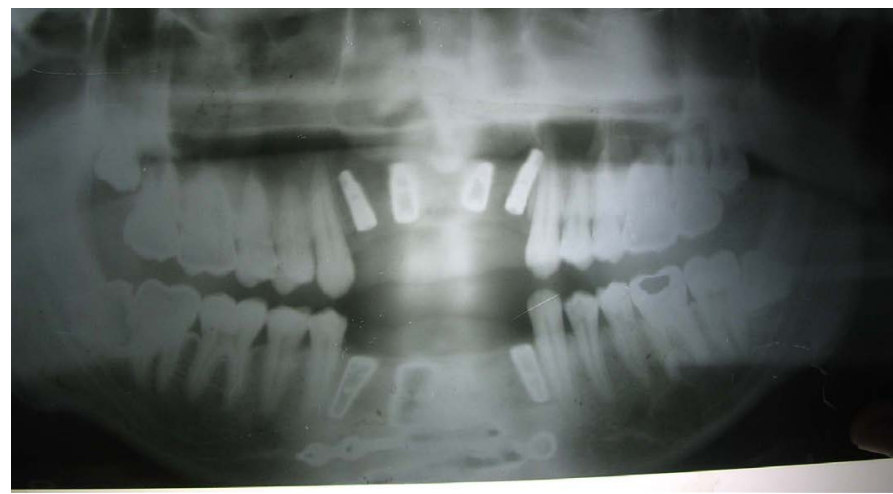

Figure 2. Radiographic assessment showing satisfactory integration of implants

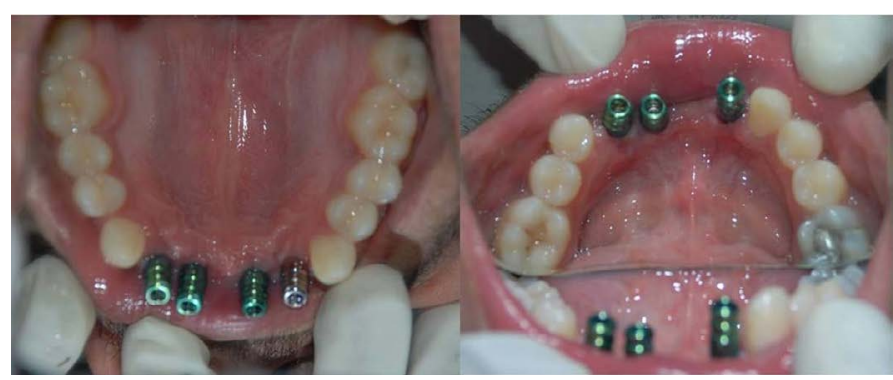

Figure 3. Impression copings placed

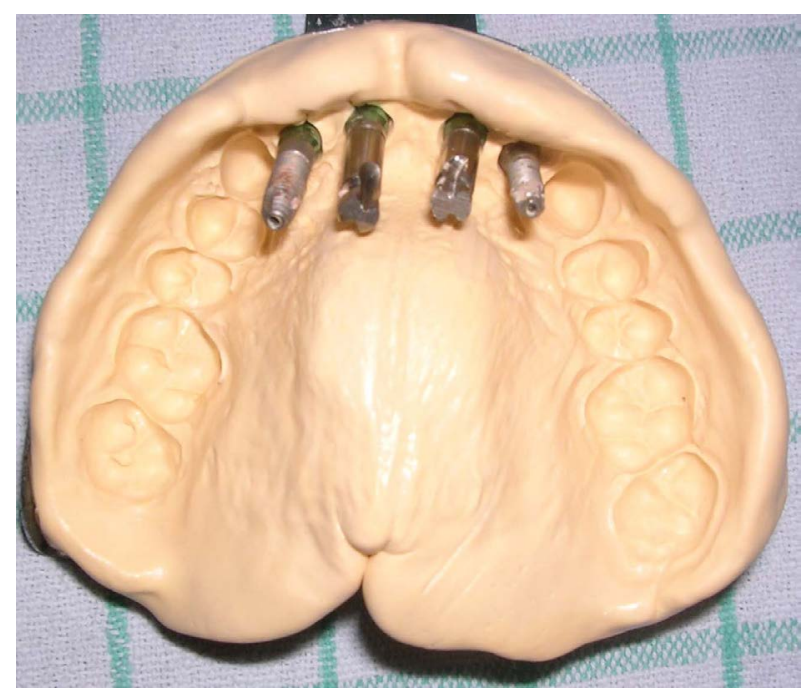

Figure 4. Elastomeric impression made to capture the position of implants

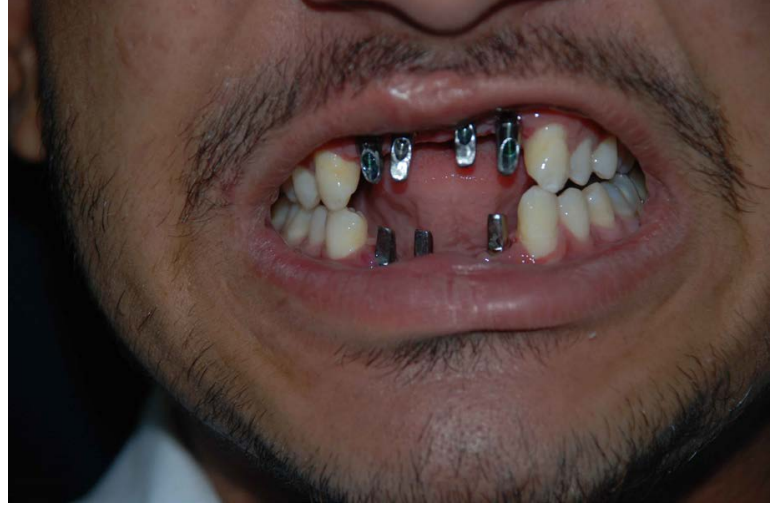

Figure 5. Abutments placed

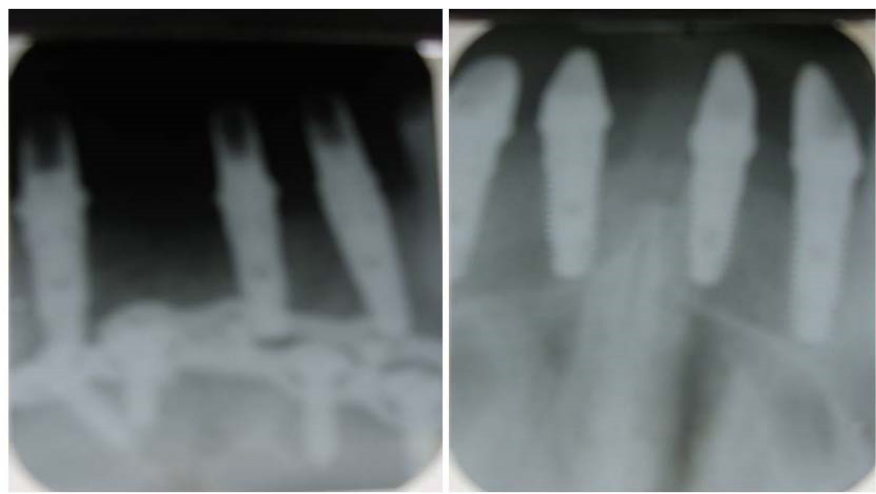

Figure 6. Radiographic confirmation of abutment seating

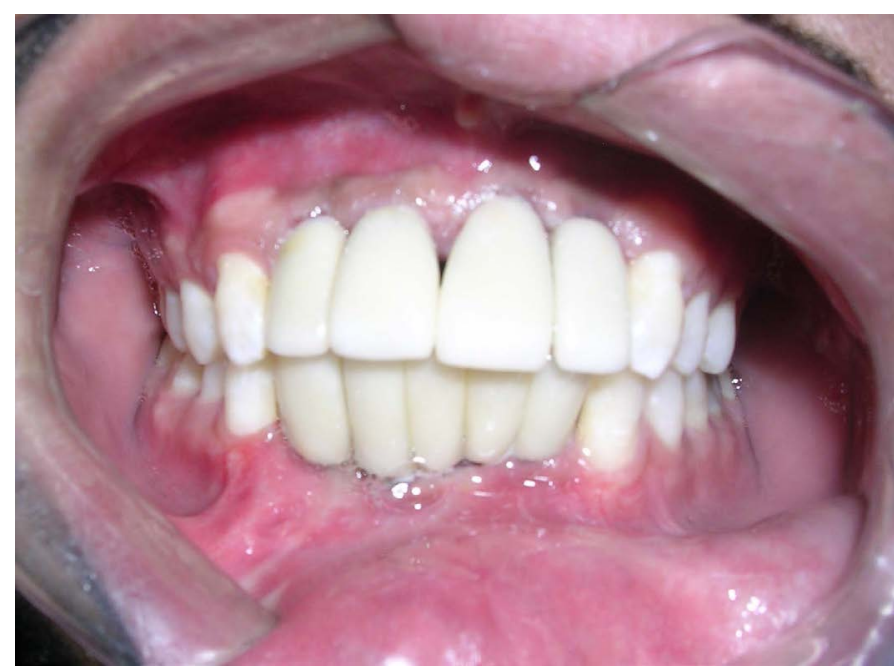

Figure 7. Porcelain fused to metal crowns cemented

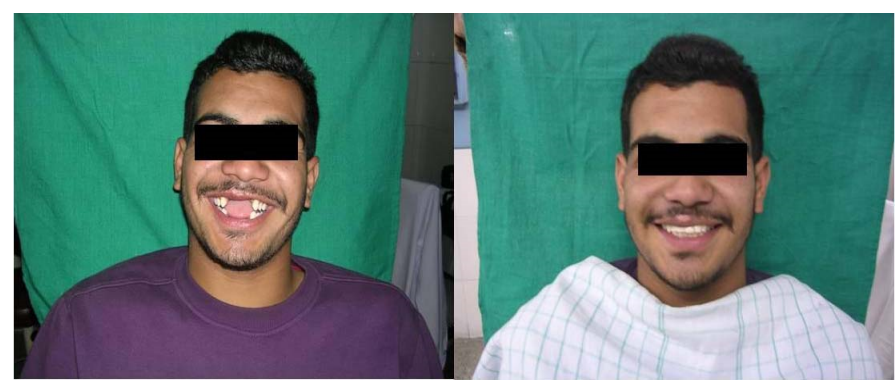

Figure 8. Comparison of pre-operative and post-operative photograph 


\section{Periodontium type}

Ochsenbein and Ross in 1969 [9] classified the periodontium into a thick flat type and a thin scalloped type. Each type was said to have different inflammatory responses to external stimuli and to periodontal treatments. In 1997, Weisgold applied the idea to implantation [10]. The patient in this case report had a thin scalloped type periodontium, which is susceptible to external stimuli and causes gingival recession. In an effort to prevent such recession, extra attention was paid in the course of constructing a restoration, like proper retraction of the marginal gingiva before making an impression.

\section{Submergence profile}

It is a vertical discrepancy between the fixture head and its adjacent cementoenamel junction. It is a vertical space necessary for a round implant with a short diameter to transform into a triangular crown cervical with a long diameter. It is also an index of guided gingival growth during a provisional phase. The submergence profile of 1-3 mm enables an optimal adjustment of the gingiva, and the profile of 4-5 $\mathrm{mm}$ promises a relatively fine adjustment, but that of over $5 \mathrm{~mm}$ makes an adjustment difficult. In order to prevent it, a surgical stent that can adjust not only the direction but also the depth of an implant fixture needs to be constructed.

\section{Gingival contour}

Peri-implant soft tissue is just like a toy balloon with water inside that can expand in any direction. Thus, an individualized healing abutment can change a form of the marginal gingival [11]

\section{Apicocoronal position}

It is closely related to the diameter of an implant and essential to an aesthetic emergence profile [12]. When the diameter of an implant is similar to that of an extracted tooth's cervical area, the distance of 3-4 $\mathrm{mm}$ is required for an aesthetic reason between a free gingival margin and implant shoulders to recover biologic width and peri-implant sulcus. Thus, the part where the abutment and the gingiva meet were made from biocompatible porcelain to maintain oral hygiene.

\section{Long axis}

The long axis of an implant determines the dimension of a crown. If a fixture is implanted in parallel with the long axis of a crown restoration, the height of a crown and a natural tooth will be the same. However, if an implant is inclined to the palatal, a restoration with a form of ridge lap will be created on the facial surface, making it hard to maintain oral hygiene [13]. In the process of implantation, a fixture tends to incline to the facial bone softer than the palatal bone. This can be prevented by blocking the labial side when a surgical stent is constructed.

\section{Occlusion}

An implant fixture does not have periodontal ligament and the surface of the root is only $145 \mathrm{~mm}^{2}$ as compared to $204 \mathrm{~mm}^{2}$ of the central incisor and $179 \mathrm{~mm}^{2}$ of the lateral incisor [14]. It is important to consider this during an occlusal adjustment. In this case, the patient's four anterior teeth had minimal contact during maximum intercuspation and no contact for protrusive \& laterotrusive movement.

\section{Thickness of marginal gingiva}

The marginal gingiva should be thick on the facial surface to prevent the appearance of metal and minimize inflammatory reaction.

\section{Conclusion}

Placement of dental implants in the maxillary anterior region requires precise planning \& surgery and demands a thorough understanding of the anatomic, biologic, surgical and prosthetic principles. The present report describes the successful prosthetic rehabilitation of maxillary anterior region in a patient using implantsupported restoration.

\section{References}

1. Bashutski JD, Wang HL (2007) Common implant esthetic complications. Implant Dent 16: 340-348. [Crossref]

2. Simeone P, De Paoli C, De Paoli S, Leofreddi G, Sgro S (2007) Interdisciplinary treatment planning for single tooth. $J$ Esthet Restor Dent 19: 79-88. [Crossref]

3. Funato A, Salama MA, Ishikawa T, Garber DA, Salama H (2007) Timing, positioning, and sequential staging in esthetic implant therapy: a four-dimensional perspective. Int $J$ Periodontics Restorative Dent 27: 313-323. [Crossref]

4. Garber DA (1996) The esthetic dental implant: letting restoration be the guide. J Oral Implantol 22: 45-50. [Crossref]

5. Kamalakidis S, Paniz G, Kang KH, Hirayama H (2007) Nonsurgical management of soft tissue deficiencies for anterior single implant-supported restorations: A clinical report. J Prosthet Dent 97: 1-5. [Crossref]]

6. Sadan A, Blatz MB, Salinas TJ, Block MS (2004) Single implant restorations: a contemporary approach for achieving a predictable outcome. J Oral Maxillofac Surg 62: 73-81. [Crossref]

7. Frank RP, Milgrom P, Leroux BG, Hawkins NR (1998) Treatment outcomes with Mandibular removable partial dentures: A population-based study of patient satisfaction. J Prosthet Dent 80: 36-45. [Crossref]

8. Berekally TL, Smales RJ (1993) A retrospective clinical evaluation of resin-bonded bridges inserted at the Adelaide Dental Hospital. Aust Dent J 38: 85-96. [Crossref]

9. Obschenbein C, Ross S (1973) A concept of osseous surgery and its clinical application In: Ward HL,Chas C, eds. A periodontal point of view. Springfield, IL: Charles L, Thomas.

10. Weisgold AS, Arnoux JP, Lu J (1997) Single-tooth anterior Implant: A word of caution. Part I. J Esthet Dent 9: 225-233. [Crossref]

11. Garber DA, Belser UC (1995) Restoration-driven implant placement with restorationgenerated site development. Compend Cont Educ Dent 16: 796-804. [Crossref]

12. Saadoun AP, Le Gall MG (1998) Periodontal implications in implant treatment planning for aesthetic results. Pract Periodont Aesthet Dent 10: 655-664. [Crossref]

13. Carl E (1999) Misch: Contemporary Implant Dentistry, 2nd.

14. Jepsen A (1963) Root surface measurement and a method for x-ray determination of root surface area. Acta Odontol Scand 21: 35-46. [Crossref]

Copyright: (C2020 Rani G. This is an open-access article distributed under the terms of the Creative Commons Attribution License, which permits unrestricted use, distribution, and reproduction in any medium, provided the original author and source are credited. 